\title{
Long-term results of patients treated with bronchoscopic lung volume reduction
}

\author{
(1) Ahmet Çağın, (1) Deniz Doğan, (1) Cantürk Taşçı \\ University of Health Sciences Turkey, Gülhane Training and Research Hospital, Clinic of Chest Disease, Ankara, Turkey
}

Date submitted:

29.11.2020

Date accepted:

22.01.2021

Online publication date:

15.09.2021

\section{Corresponding Author:}

Ahmet Çağın, M.D., University of Health Sciences Turkey, Gülhane Training and Research Hospital, Clinic of Chest Disease, Ankara, Turkey drahmetcagin@gmail.com

ORCID:

orcid.org/0000-0002-5526-6506

Keywords: Emphysema, bronchoscopic lung volume reduction, endobronchial valve, lung volume reduction coil, respiratory function tests

\begin{abstract}
Aims: Surgical and bronchoscopic treatments are tried to reduce hyperinflation together with medical treatments in patients with chronic obstructive pulmonary disease (COPD) and emphysema. Therefore, bronchoscopic lung volume reduction (BLVR) procedures can improve the success of treatment and quality of life of patients.
\end{abstract}

Methods: We investigated the efficacy and safety of BLVR treatment retrospectively. Demographic characteristics, modified Medical Research Council (mMRC) and COPD assessment test (CAT) questionnaires, 6-minute walking distance (6-MWD) and all pulmonary function tests of the patients, who were treated with BLVR, were examined. The values before the procedure and the values at the third and sixth months after the procedure were analyzed statistically.

Results: Twenty-five patients were examined (one was female). Six patients $(59 \pm 10.4$ years, forced expiratory volume in $1 \mathrm{~s}$ (FEV1) $21.7 \pm 5.7 \%$ pred) were bronchoscopically treated with coils, with a median of 9.33 (range $8-11$ ) coils per procedure. Nineteen patients $(65.8 \pm 6$ years, FEV1 $26.9 \pm 9 \%$ pred) were treated with valves, with a median 3.52 (range 3-4) valves per patient. At 3 and 6 months, respectively, $\triangle$ CAT was $-4.8 \pm 6$ and $-7.5 \pm 7.2$ points, $\Delta 6-M W D$ was $+103.4 \pm 139 \mathrm{~m}$ and $+160.8 \pm 149 \mathrm{~m}$ [endobronchial valve (EBV)], $\triangle \mathrm{FEV} 1$ was $+0.15 \pm 0.3 \mathrm{~L}$ and $+0.21 \pm 0.3 \mathrm{~L}, \Delta \mathrm{FVC}$ was $+0.44 \pm 0.7 \mathrm{~L}$ and $+0.5 \pm 0.7 \mathrm{~L}$, (all $\mathrm{p}<0.05)$, and $\Delta \mathrm{RV}$ (residual volume) was $-0.52 \pm 1.1 \mathrm{~L}$ and $0.32 \pm 1.5 \mathrm{~L}(\mathrm{p}>0.05)$.

Conclusions: In our study, BLVR (EBV and coil) treatments were used in patients with severe to very severe emphysema in COPD, in appropriate indications and in selected cases, and statistically significant well-being was observed in spirometric parameters in the first six months after the procedure.

\section{Introduction}

Chronic obstructive pulmonary disease (COPD) is a disease with persistent respiratory symptoms due to airway and/or alveolar abnormalities and is associated with a more or less emphysema phenotype (1), which is the dominant pathological feature of COPD. It is observed with damage and progressive condition in the terminal bronchioles and distal airways (2). Loss of lung elastic recoil results in airflow obstruction, leading to gas compression and increased lung volumes $(3,4)$. Among the current standard treatment options for COPD, the most important ones are smoking cessation and pharmacological treatments. In addition, there is respiratory rehabilitation applied in specialized centers (1). Despite optimal pharmacological treatment in COPD patients with a predominant emphysema phenotype, pharmacological treatments are insufficient and medical treatment does not prevent the progression of the disease in these patients $(5,6)$.

Since 2002, several bronchoscopic interventions have been evaluated in clinical trials. The aim is to reduce hyperinflation and thus improve respiratory mechanics (7). Many clinical studies have shown positive effects on patients. After bronchoscopic interventions, a decrease in symptoms due to residual volume reduction is observed and an increase in quality of life is observed (6). Bronchoscopic interventions for lung volume reduction basically include reversible and irreversible blocking techniques. The choice of the different bronchoscopic lung volume reduction (BLVR) techniques depends on expert bronchoscopists. The distribution of emphysema is important in this decision, and the 
evaluation of collateral ventilation determines the success of the procedure. However, positive results are obtained with the appropriate technique for the appropriate patient.

In our study, we aimed to examine the changes in the symptoms of patients who were applied BLVR treatment, and to examine the changes in spirometry, lung volumes and diffusion lung capacity of carbon monoxide (DLCO) test in respiratory function tests.

\section{Methods}

\section{Study Design}

The clinical records of patients were retrospectively reviewed between October 2017 and October 2019. Patients with severe to very severe emphysema, who underwent endobronchial valve (EBV) and lung volume reduction coil (LVRC) placement, were included.

NETT study criteria were accepted for inclusion criteria and exclusion criteria in this study. Inclusion criteria were as follows: Being $>18$ years of age, having CT scan showing heterogeneous emphysema (criteria for EBV only), GOLD Stage 3 or 4, post-bronchodilator forced expiratory volume first second (FEV1) $<50 \%$ of predicted, residual volume (RV) $>150 \%$ of predicted, total lung capacity (TLC) $>100 \%$ of predicted, DLCO $>20 \%$ of predicted, 6-minutes walking distance test (6-MWD) $<500$ meters, systolic pulmonary artery pressure $<50 \mathrm{mmHg}$ on echocardiography, using optimal bronchodilator therapy, at least 6 weeks of pulmonary rehabilitation and having stopped smoking for $>8$ weeks prior to the study. Exclusion criteria included having with pregnancy or lactation status, active lung cancer, history of frequent respiratory tract infections, giant bullae in the lungs, clinically significant bronchiectasis, history of lung volume reduction surgery, transplantation or lobectomy history and having collateral ventilation (criteria for EBV only).

Demographic characteristics of patients, including age, gender, height, weight, body mass index (BMI), duration of illness, comorbidity, smoking history, drugs used, and first and second visits, were recorded using the data preparation form.

COPD assessment tests (CAT) and modified Medical Research Council (mMRC) dyspnea scoring were used to assess dyspnea. $\mathrm{mMRC}$ is a scale system with scores between 0 and 4 . With a few simple questions asked to patients, the patient with the least symptoms is given a low score, and the patient with the most symptoms is given a high score. CAT score, on the other hand, is a scoring used for the evaluation of patients with COPD, which is formed by adding scores between 0 and 5 given to 8 different questions. 0 is the score obtained by the patients with the lowest symptoms and 40 by the patients with the most symptoms (8).

The results of the 6-MWD applied in the pulmonary rehabilitation unit were examined (9). BODE index, consisting of
BMI, airway obstruction, dyspnea, and exercise capacity, were calculated.

Measurements were made with a COSMED, MINISIPIR brand spirometer, which can measure within the volume limits of 15 seconds, volumes up to $20 \mathrm{~L}$, the total resistance of all parts in the range of $0.02-20 \mathrm{~L} / \mathrm{s}$. For FRC, RV and TLC measurements, a multi-term nitrogen washout test with a VMAX brand device (cardiopulmonary exercise testing ergo spirometer device) was used. The most commonly used method in DLCO measurement is the single breath $\mathrm{CO}$ method. Gas concentrations are measured at the beginning and at the end of 10 seconds.

The third month after the procedure was the first endpoint and the sixth month was the second endpoint. Baseline tests and post-procedure tests were compared.

\section{Procedure}

All patients were hospitalized before the procedure. Patients with dyspnea after procedure were given systemic steroids against foreign body reaction. All patients were admitted to hospital for a period of 3 to 5 days. A posteroanterior chest X-ray was routinely obtained following the procedure.

\section{Endobronchial Valve}

The EBV procedures were done using a flexible bronchoscope (BF-1TQ180 Olympus, Tokyo, Japan) with a working channel of $2.8 \mathrm{~mm}$. The procedure was under conscious sedation with intravenous midazolam. High resolution computerized tomography (HRCT) with thin slice imaging and quantitative lung perfusion scintigraphy were used to choose the target lobe. Chartis collateral ventilation system (Pulmonx, Redwood City, CA, USA) was used to detect collateral ventilation (Zephyr Tm EBV, Pulmonx Inc., Redwood, CA, USA).

\section{Lung Volume Reduction Coil}

LVRC procedures were performed under general anesthesia. HRCT with thin slice and quantitative lung perfusion scintigraphy were used to choose the target lobe. Following the patient's intubation, the coils (Coil, PneumRx Inc. Mountain View, California, USA) were placed into the subsegmental airway with fluoroscopy guidance.

\section{Statistical Analysis}

Our study includes a retrospective analysis of patients who underwent BLVR therapy. Statistical Package for the Social Sciences (SPSS) for Mac version 22.00 (SPSS Inc., Chicago, IL., USA) package program was used for the statistical analysis of the data obtained at the end of the study. Data were given as mean and standard deviation (SD). Continuous variables were expressed as mean $\pm S D$, and categorical variables as numbers and percentages (\%). Whether continuous variables fit the normal distribution or not was evaluated using the KolmogorovSmirnov test. For the comparison of groups, the chi-square test 


\begin{tabular}{|c|c|c|c|}
\hline & EBV $(n=19)$ & LVRC (n=6) & Total $(n=25)$ \\
\hline Variable & Mean $\pm S D$ & Mean士SD & Mean $\pm S D$ \\
\hline Age, year & $65.8 \pm 6.0$ & $59.0 \pm 10.4$ & $64.1 \pm 7.7$ \\
\hline BMI & $21.9 \pm 5.0$ & $24.6 \pm 4.3$ & $22.6 \pm 4.9$ \\
\hline $\begin{array}{l}\text { Smoking, pack/ } \\
\text { year }\end{array}$ & $52.3 \pm 15.6$ & $50.8 \pm 41.4$ & $51.9 \pm 23.5$ \\
\hline $\begin{array}{l}\text { First diagnosis, } \\
\text { year }\end{array}$ & $10.2 \pm 3.9$ & $8.3 \pm 4.5$ & $9.7 \pm 4.0$ \\
\hline \multicolumn{4}{|l|}{$\begin{array}{l}\text { Pulmonary } \\
\text { function }\end{array}$} \\
\hline FVC, L & $2.23 \pm 0.60$ & $2.27 \pm 0.69$ & $2.24 \pm 0.61$ \\
\hline FVC, \% pred & $63.3 \pm 16.8$ & $58.5 \pm 17.5$ & $62.1 \pm 16.7$ \\
\hline FEV1, L & $0.74 \pm 0.23$ & $0.66 \pm 0.15$ & $0.72 \pm 0.21$ \\
\hline FEV1, \% pred & $27.0 \pm 8.1$ & $21.6 \pm 5.7$ & $25.7 \pm 7.9$ \\
\hline FEV1/ FVC & $34.1 \pm 10.5$ & $29.8 \pm 3.5$ & $33.1 \pm 9.4$ \\
\hline TLC, L & $6.88 \pm 0.93$ & $6.17 \pm 2.06$ & $6.72 \pm 1.24$ \\
\hline TLC, $\%$ pred & $112.1 \pm 18.0$ & $94.4 \pm 30.9$ & $108.3 \pm 21.9$ \\
\hline $\mathrm{RV}, \mathrm{L}$ & $4.57 \pm 0.98$ & $3.78 \pm 1.34$ & $4.40 \pm 1.08$ \\
\hline $\mathrm{RV}, \%$ pred & $193.1 \pm 44.5$ & $159.4 \pm 52.4$ & $185.8 \pm 47.3$ \\
\hline $\begin{array}{l}\text { RV/TLC, \% } \\
\text { pred }\end{array}$ & $66.5 \pm 7.79$ & $61.0 \pm 6.2$ & $65.3 \pm 7.7$ \\
\hline$V C, L$ & $2.31 \pm 0.53$ & $2.38 \pm 0.86$ & $2.33 \pm 0.59$ \\
\hline VC, \% pred & $62.7 \pm 11.9$ & $59.4 \pm 21.5$ & $61.9 \pm 13.9$ \\
\hline DLCO, \% pred & $35.7 \pm 12.1$ & $37.4 \pm 7.7$ & $36.1 \pm 11.1$ \\
\hline \multicolumn{4}{|l|}{$\begin{array}{l}\text { Arterial blood } \\
\text { gas }\end{array}$} \\
\hline $\mathrm{pH}$ & $7.43 \pm 0.38$ & $7.39 \pm 0.33$ & $7.42 \pm 0.39$ \\
\hline $\mathrm{pCO}_{2}, \mathrm{mmHg}$ & $3685 \pm 5.88$ & $41.26 \pm 6.26$ & $37.77 \pm 6.10$ \\
\hline $\mathrm{pO}_{2}, \mathrm{mmHg}$ & $64.15 \pm 16.14$ & $70.42 \pm 12.05$ & $65.45 \pm 15.36$ \\
\hline $\mathrm{sO}_{2}, \%$ & $90.03 \pm 8.32$ & $94.04 \pm 1.53$ & $90.86 \pm 7.58$ \\
\hline $\mathrm{FCOHb}$ & $1.81 \pm 0.83$ & $1.72 \pm 0.31$ & $1.79 \pm 0.75$ \\
\hline $\mathrm{HCO}_{3}$ & $24.16 \pm 3.22$ & $24.62 \pm 2.15$ & $24.25 \pm 2.99$ \\
\hline PAPs, mmHg & $23.6 \pm 7.7$ & $27.0 \pm 6.7$ & $24.3 \pm 7.5$ \\
\hline mMRC, point & $3.63 \pm 0.49$ & $3.66 \pm 0.52$ & $3.64 \pm 0.49$ \\
\hline CAT, point & $26.26 \pm 7.03$ & $24.66 \pm 4.27$ & $25.88 \pm 6.43$ \\
\hline BODE, point & $8.11 \pm 1.37$ & $7.83 \pm 1.33$ & $8.04 \pm 1.33$ \\
\hline 6-MWD, m & $182.5 \pm 122.3$ & $219.1 \pm 124.2$ & $191.3 \pm 121.2$ \\
\hline \multicolumn{4}{|c|}{ 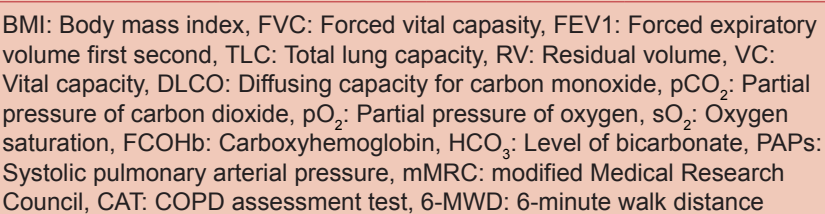 } \\
\hline
\end{tabular}

was used for discrete variables, and for continuous variables (such as FEV1, DLCO, mMRC, and age) the Wilcoxon paired two-sample test or paired samples t-test was used according to the presence of normal distribution. Statistical significance was taken as $p<0.05$.

\begin{tabular}{|c|c|c|}
\hline & $\begin{array}{l}\text { Endobronchial } \\
\text { valve }(n=19)\end{array}$ & $\begin{array}{l}\text { Endobronchial } \\
\text { coil }(n=6)\end{array}$ \\
\hline \multicolumn{3}{|l|}{ Target lobe, patient head } \\
\hline Right upper lobe, n (\%) & $14(73)$ & $2(33)$ \\
\hline $\begin{array}{l}\text { Right upper + left upper lobe } \\
\mathrm{n}(\%)\end{array}$ & 0 & $3(50)$ \\
\hline Right upper + middle lobe $\mathrm{n}(\%)$ & $1(5.3)$ & 0 \\
\hline Right lower lobe n (\%) & $1(5.3)$ & 0 \\
\hline Left upper lobe n (\%) & $2(10.6)$ & $1(17)$ \\
\hline Left lower lobe n (\%) & $1(5.3)$ & 0 \\
\hline $\begin{array}{l}\text { Number of valves/coils, } \\
\text { per patient }\end{array}$ & 3.52 & 14 \\
\hline $4.0 / 100 \mathrm{~mm} \mathrm{n} \mathrm{( \% )}$ & $36(54)$ & $59(70)$ \\
\hline 4.0 LP / 125 mm n (\%) & $3(4)$ & $25(30)$ \\
\hline $5.5 \mathrm{n}(\%)$ & $28(42)$ & - \\
\hline Total & $67(100)$ & $84(100)$ \\
\hline $\begin{array}{l}\text { Hospital stay after operation, } \\
\text { days }\end{array}$ & $4.5 \pm 2.6(2-13)$ & $3.5 \pm 1.2(3-6)$ \\
\hline
\end{tabular}

\section{Results}

A total of 28 patients were identified, 3 patients were excluded due to exclusion criteria. EBV was performed in 19 patients and LVRC was performed in 6 patients. One procedure was performed for 19 valve patients and a second procedure was performed for 3 of 6 coil patients, and a total of 28 procedures were performed.

Twenty-four patients were male and one was female. The mean age of all patients was $64.1 \pm 7.7$ (48-80) years. Twentythree patients had a smoking history, and the average of all patients was calculated as $51.9 \pm 23.5$ packs/year. Two patients had biomass exposure. The demographic and clinical characteristics of EBV and LVRC groups before the treatment were similar. The average of the tests performed before the procedure is given in Table 1.

A total of 67 valves were used, and the average per patient was 3.52. And total of 84 coils were used, the number of coils used was 9.33 per procedure and an average of 14 per patient. The right upper lobe was frequently used. Details of procedure are given in Table 2.

While there were no comorbid diseases in 10 patients in their anamnesis and medical records taken before the treatment, cardiac arrhythmia was seen in 5 patients, hypertensive heart disease in 4 patients, coronary/peripheral artery disease in 4 patients, diabetes mellitus in 1 patient, and mild systolic heart failure in 2 patients. Two patients had second degree heart valve failure, 2 patients had hypothyroidism, and 1 patient used drugs for depression.

While bronchospasm was observed most frequently in patients $(n=11)$, hemoptysis was observed following the LVRC 


\begin{tabular}{|c|c|c|}
\hline & (0-30 days) & (31-180 days) \\
\hline Bronchospasm, n (\%) & $11(44)$ & 0 \\
\hline Hemoptysis, n (\%) & $1(4)$ & 0 \\
\hline Pneumothorax, n (\%) & $1(4)$ & 0 \\
\hline Pneumonia, n (\%) & $2(8)$ & $2(8)$ \\
\hline COPD exacerbation, n (\%) & $4(16)$ & $2(8)$ \\
\hline $\begin{array}{l}\text { Subcutaneous emphysema, } \\
\mathrm{n}(\%)\end{array}$ & $1(4)$ & 0 \\
\hline Valve migration, $\mathrm{n}(\%)$ & $1(4)$ & 0 \\
\hline Death, $n(\%)$ & $0(0)$ & $1(4)$ \\
\hline
\end{tabular}

procedure in 1 patient and pneumothorax and subcutaneous emphysema following EBV procedure in another patient. One patient died on the second month following EBV therapy secondary to COPD exacerbation (Table 3 ).

The mMRC dyspnea scores, CAT scores, BODE index and 6-MWD data recorded in the third and sixth months after the procedure were statistically significant. Forced vital capacity (FVC) and vital capacity (VC) measurements of all patients were statistically significant at the $3^{\text {rd }}$ and $6^{\text {th }}$ months after the procedure $(p<0.05)$.

The mean FEV1 value at the $3^{\text {rd }}$ month of the patients who underwent EBV was $0.88 \pm 0.3 \mathrm{~L}(\mathrm{p}=0.041)$, and the mean FEV1 value at the $6^{\text {th }}$ month after the procedure was $0.92 \pm 0.4 \mathrm{~L}$ $(p=0.102)$. FEV1 value change was $0.14 \pm 0.25 \mathrm{~L}$ at the $3^{\text {rd }}$ month and $0.18 \pm 0.3 \mathrm{~L}$ at the $6^{\text {th }}$ month. The mean FEV1 value at the $3^{\text {rd }}$ month of the patients who underwent LVRC was $0.81 \pm 0.2$ $L(p=0.003)$, and the mean FEV1 value at the $6^{\text {th }}$ month after the procedure was $0.92 \pm 0.2 L(p=0.104)$. When the FEV1 percentages were examined one by one, according to the basal values, the increase in FEV1 of $12 \%$ was observed in all 6 patients. The mean FEV1 value of all patients was $0.86 \pm 0.3 \mathrm{~L}$ $(p=0.005)$ at the $3^{\text {rd }}$ month after the procedure, and the mean FEV1 value of all patients was $0.92 \pm 0.4 L(p=0.035)$ at the $6^{\text {th }}$ month after the procedure. The mean FEV1 value change of all patients was $0.15 \pm 0.3 \mathrm{~L}$ at the $3^{\text {rd }}$ month and $0.21 \pm 0.3 \mathrm{~L}$ at the $6^{\text {th }}$ month. After the procedure, an increase was observed in 17 $(68 \%)$ of the patients in our study, compared to the previous FEV1 value. A total of 14 patients (56\%) had an average increase of $12 \%$ in FEV1.

The mean RV percentage was $169.2 \pm 37.6 \% \quad(p=0.058)$ at the $3^{\text {rd }}$ month of the patients who underwent EBV, and the mean $\mathrm{RV}$ percentage at the $6^{\text {th }}$ month after the procedure was $179.6 \pm 72.1 \%(p=0.365)$. The mean RV value of patients who underwent EBV decreased by $0.75 \pm 0.9 \mathrm{~L}(\mathrm{p}=0.066)$ at the $3^{\text {rd }}$ month and by $0.5 \pm 1.4 \mathrm{~L}(\mathrm{p}=0.442)$ at the $6^{\text {th }}$ month compared to the baseline. The mean RV percentage at the $3^{\text {rd }}$ month of the patients who underwent LVRC was $169.6 \pm 49.2 \%(p=0.681)$, and

\begin{tabular}{|c|c|c|c|c|}
\hline & \multicolumn{2}{|l|}{ EBV } & \multicolumn{2}{|l|}{ LVRC } \\
\hline & $\Delta$ & $\begin{array}{l}p \\
\text { value }\end{array}$ & $\Delta$ & $\begin{array}{l}p \\
\text { value }\end{array}$ \\
\hline FVC, \% pred & $-5.9 \pm 18.5$ & 0.203 & $-27.2 \pm 18.8$ & 0.001 \\
\hline FEV1, \% pred & $-4.9 \pm 9.6$ & 0.044 & $-5.6 \pm 6.9$ & 0.016 \\
\hline TLC, \% pred & $10.7 \pm 19.7$ & 0.126 & $-20.6 \pm 27.8$ & 0.109 \\
\hline $\mathrm{RV}, \%$ pred & $32.9 \pm 41.7$ & 0.058 & $-10.2 \pm 50.7$ & 0.681 \\
\hline VC, \% pred & $-5.9 \pm 16.6$ & 0.108 & $-37.6 \pm 15.2$ & 0.012 \\
\hline DLCO, \% pred & $-1.7 \pm 16.6$ & 0.678 & $-19.8 \pm 16.9$ & 0.147 \\
\hline mMRC, point & $0.8 \pm 0.7$ & 0.010 & $0.8 \pm 0.45$ & 0.033 \\
\hline CAT, point & $4.5 \pm 6.2$ & 0.018 & $4.8 \pm 5.5$ & 0.033 \\
\hline BODE, point & $1.8 \pm 1.4$ & 0.026 & $2 \pm 1.4$ & 0.089 \\
\hline 6-MWD, m & $-107.5 \pm 121.4$ & 0.082 & $-106.2 \pm 126.3$ & 0.091 \\
\hline \multicolumn{5}{|c|}{$\begin{array}{l}\text { *FVC: Forced vital capasity, FEV1: Forced expiratory volume first second, } \\
\text { TLC: Total lung capacity, RV: Residual volume, VC: Vital capacity, DLCO: } \\
\text { Diffusing capacity for carbon monoxide, mMRC: Modified Medical Research } \\
\text { Council, CAT: COPD assessment test, 6-MWD: 6-minute walk distance, LVRC: } \\
\text { Lung volume reduction coil }\end{array}$} \\
\hline
\end{tabular}

\begin{tabular}{|c|c|c|c|c|}
\hline \multicolumn{5}{|c|}{ Tablo 5. Outcomes at the $6^{\text {th }}$ month } \\
\hline & \multicolumn{2}{|l|}{ EBV } & \multicolumn{2}{|l|}{ LVRC } \\
\hline & $\Delta$ & $\begin{array}{l}p \\
\text { value }\end{array}$ & $\Delta$ & $\begin{array}{l}\mathbf{p} \\
\text { value }\end{array}$ \\
\hline FVC, \% pred & $-8.8 \pm 18.3$ & 0.065 & $-24.2 \pm 19$ & 0.030 \\
\hline FEV1, \% pred & $-5.3 \pm 11$ & 0.086 & $-8.6 \pm 7.8$ & 0.133 \\
\hline TLC, \% pred & $5.7 \pm 20.8$ & 0.454 & $-11.2 \pm 26.9$ & 0.556 \\
\hline RV, \% pred & $23.5 \pm 56.9$ & 0.365 & $-18.3 \pm 73.5$ & 0.687 \\
\hline VC, \% pred & $-8.3 \pm 16.2$ & 0.085 & $-11.6 \pm 16.4$ & 0.195 \\
\hline DLCO, \% pred & $-9.7 \pm 20.2$ & 0.300 & $-3.1 \pm 11.3$ & 0.205 \\
\hline mMRC, point & $1.2 \pm 0.75$ & 0.005 & $1.5 \pm 1$ & 0.383 \\
\hline CAT, point & $6.7 \pm 7.45$ & 0.011 & $9.3 \pm 5.5$ & 0.115 \\
\hline BODE, point & $1.9 \pm 1.65$ & 0.009 & $1.7 \pm 2$ & 0.369 \\
\hline 6-MWD, m & $-171.2 \pm 134$ & 0.021 & $-172.7 \pm 111.5$ & 0.034 \\
\hline \multicolumn{5}{|c|}{$\begin{array}{l}\text { *FVC: Forced vital capasity, FEV1: Forced expiratory volume first second, } \\
\text { TLC: Total lung capacity, RV: Residual volume, VC: Vital capacity, DLCO: } \\
\text { Diffusing capacity for carbon monoxide, mMRC: Modified Medical Research } \\
\text { Council, CAT: COPD assessment test, 6-MWD: 6-minute walk distance, LVRC } \\
\text { Lung volume reduction coil }\end{array}$} \\
\hline
\end{tabular}

the mean $\mathrm{RV}$ percentage at the $6^{\text {th }}$ month after the procedure was $177.7 \pm 94.6 \%(p=0.687)$. The mean $R V$ value of patients who underwent LVRC increased by $0.07 \pm 1.15 \mathrm{~L}(\mathrm{p}=0.898)$ at the $3^{\text {rd }}$ month and by $-0.11 \pm 1.45 \mathrm{~L}(\mathrm{p}=0.735)$ at the $6^{\text {th }}$ month compared to the baseline. Third-and sixth-month test changes of all patients are given in Table 4 and 5 .

\section{Discussion}

Cessation of smoking and traditional medical treatments have been shown to be effective in COPD at first, but the effectiveness of these treatment modalities in preventing exercise dyspnea is limited (10). In the GOLD 2017 report, it is atated that "in selected patients with heterogeneous or 
homogeneous emphysema and significant hyperinflation despite optimized medical care, surgical or BLVR methods (eg. EBV one-way valves or coils) may be considered" (11).

In this study, the short-term effectiveness and safety of BLVR procedures in patients with emphysema who received optimal medical therapy were evaluated. Improvements were observed in the exercise capacity, quality of life and pulmonary function parameters of the patients after the procedure. The mMRC dyspnea scores, CAT scores, BODE index and 6-MWD data recorded at the $3^{\text {rd }}$ and $6^{\text {th }}$ months after the procedure were statistically significant. FEV1, FVC and VC measurements of patients were statistically significant at the third and sixth months after the procedure $(p<0.05)$. When we look at the literature, in many studies, FEV1 value and percentage increase together with the decrease in RV values and percentages are used to evaluate the effectiveness of BLVR. Meta-analyses compiled from these studies frequently include the change in these values of patients $(2,4,12)$.

While the mean baseline FEV1\% values of the patients in previous BLVR studies ranged between $26 \%$ and $33.4 \%$, the FEV1\% values in the RENEW and REVOLENS studies were the closest values to our study with $26 \%$ and $26.3 \%$ (12-14). The mean increases in FEV1 of our patients who underwent EBV was $180 \mathrm{~mL}$ and it was observed to be more than $100 \mathrm{~mL}$, which is the minimal significant value. Davey et al. (6) reported an increase in FEV1 of $60 \mathrm{~mL}$ and $8.7 \%$ in the 6-month followup in the EBV series of 25 patients. And, Klooster et al. (15) reported that there was $147 \mathrm{~mL}$ increase in the EBV group with 40 patients. In the prospective multicenter randomized controlled TRANSFORM study published in 2017, the highest mean value was recorded as $230 \mathrm{~mL}$ and a significant increase in FEV1 $(12 \%)$ was observed in $66 \%$ of the patients $(p<0.001)$ (16). Valipour et al. (17) in a prospective study of 93 patients, in which 43 patients undergoing EBV were compared with standard treatment, showed an increase of $120 \mathrm{~mL}$ and a FEV $1 \%$ improvement of $3.5 \%$ versus $13.7 \%$ in their 6 -month follow-up compared to the control group ( $p=0.002)$, and it was noted that 14 patients (42\%) who underwent the procedure had an increase of $100 \mathrm{~mL}$ and over $12 \%$. When compared to this study, it was observed that $56 \%$ of our patients had an increase of $12 \%$ and $100 \mathrm{~mL}$.

Decrease in $\mathrm{RV}$ is accepted as one of the first endpoints with the increase of FEV1 in BLVR studies. Although the change in the mean RV values of our patients who underwent EBV was more than $350 \mathrm{~mL}$, which was considered significant change with $500 \mathrm{~mL}$ at the end of the $6^{\text {th }}$ month, it was not statistically significant. When looking at other EBV studies in 2016 and beyond; Valipour et al. (17) found a reduction in mean RV of 480 $\mathrm{mL}(\mathrm{n}=43)$, Klooster et al. (15) $672 \mathrm{~mL}(\mathrm{n}=40)$, Kemp et al. (16) $670 \mathrm{~mL}(\mathrm{n}=65)$. It is observed that our EBV patients are close to these values with the continuation of $750 \mathrm{~mL}$ at the $3^{\text {rd }}$ month and $500 \mathrm{~mL}$ at the $6^{\text {th }}$ month. As a long-term follow-up for 60 months, Fiorelli et al. (18) gave a reduction rate of approximately $39 \%$ from $247 \%$ to $207 \%$ in EBV patients in their article in 2017 , but the most important change in this study is 0-3 months (it was $41 \%$ ) and then small changes were observed in $\pm 0-3 \%$ values. This suggests that the most important change occurred in the first 3 months. In our study, the most important change occurred in the first 3 months.

In our patients who underwent LVRC, the mean increases in FVC at the $3^{\text {rd }}$ and $6^{\text {th }}$ months were statistically significant and the change was greater while the basal FVC\% values were lower than those who underwent EBV. Similarly, the VC\% change was statistically significant at the end of the $3^{\text {rd }}$ month.

In the 6-MWT values in which the exercise capacity of the patients was measured, an average increase of more than 100 $\mathrm{m}$ was observed in the patients who underwent EBV and LVRC at the $3^{\text {rd }}$ month, but statistically $p>0.05$ was not considered significant. The increase in exercise capacity continued at the $6^{\text {th }}$ month and was statistically significant. In a meta-analysis of 140 patients who underwent LVRC in 2015, Slebos et al. (19) reported an increase of $44.1 \mathrm{~m}(\mathrm{p}<0.001)$ in the mean 6-MWT distance at the $6^{\text {th }}$ month. In the review by Gülşen (2), in which BLVR treatments were evaluated in 2018, they reported an increase of $40.8 \mathrm{~m}$ (9.3-91 m) in EBV and $47 \mathrm{~m}(14.6-84 \mathrm{~m})$ in LVRC procedures. Similarly, in the systematic meta-analysis published in 2019 by Rustagi et al. (4), $39.8 \mathrm{~m}$ (18-61 m) increase in EBV and $33.5 \mathrm{~m}(5.8-61.1 \mathrm{~m})$ increase in LVRC were reported. Usually, 3-6-12-month follow-up is reported in all studies. In a single study that can be considered as a long-term follow-up, the mean change in a series of 33 patients after 5 years of follow-up was reported as $+91 \mathrm{~m}$ (18). In our patients, the highest values in 6-MWT values were usually observed at the $3^{\text {rd }}$ month, and in 5 patients $(20 \%)$, walking distance continued to increase at the $6^{\text {th }}$ month.

In our study, mMRC dyspnea scoring was used to evaluate shortness of breath in patients with COPD. The change in $\mathrm{mMRC}$ dyspnea score of the patients was considered significant in both groups. In the GOLD guideline, it is absolutely recommended to use $\mathrm{mMRC}$ and/or CAT scores for symptom scoring, and they are used to evaluate the severity of the disease (1). The CAT is a more detailed evaluation questionnaire than mMRC that examines different symptoms together. The changes in mean CAT scores of the patients in both groups were statistically significant. Similarly, in the REACH study, the mean change in CAT scores of 107 people in the $6^{\text {th }}$ month was found to be statistically significant $(p=0.017)(19,20)$. Similarly, an average decrease of 2 points was recorded in the BeLieVeR study (6). It is known that CAT score is highly correlated with quality of life. The BODE index was developed for the evaluation of mortality risk in COPD, and it was also used for hospitalization and evaluation of response to treatment. Significant improvements 
were observed in the mean BODE index change in the EBV group in our patients. It was observed that significant results including dyspnea scale (mMRC) and exercise capacity (6MWT) were also reflected in the change in BODE index.

The secondary goal of BLVR treatments is to evaluate their safety. In the first 6 months of follow-up, 1 patient died. When we look at the literature, Davey et al. (6) reported a mortality rate of $8 \%$ after 6 months of follow-up in their series of 25 cases. On the other hand, in the study of Herth et al. (21) which included 111 patients, the mortality rate was $5.4 \%$ at the end of the $12^{\text {th }}$ month. Considering the mortality rates in LVRC studies, Deslée et al. (13) reported $8 \%$ in their 50 -case study in 2016 , and Sciurba et al. (14) reported 6.5\% mortality in the 12-month follow-up of 158 cases (13). In the continuation study evaluating the long-term results of the STELVIO study, which is another study evaluating the effectiveness of EBV, it was reported that mortality was observed in only 2 patients after 12 months of 64 patients who did not have collateral ventilation (15).

In a study conducted in our country, Tanriverdi et al. (22) observed that mortality was observed in a total of 7 patients in their 12-month follow-up study in which complications of a total of 66 patients (37 patients EBV, 29 patients LVRC) who underwent EBV or LVRC were evaluated. The researchers reported that 4 of these patients who underwent EBV and 3 who underwent LVRC died. And the annual mortality rate was $10.6 \%$. The main issue highlighted in this study was that all patients with mortality had at least one additional disease and the mortality rate was higher in the presence of more than one additional disease, especially in the LVRC group. Although one case in our study had pneumothorax and another patient had hemoptysis, no mortality was observed in the perioperative and postoperative acute period. In an article in which studies published between 2010 and 2017 were compiled, it was reported that COPD exacerbation, followed by pneumonia and pneumothorax, was observed most commonly in those who underwent EBV and LVRC. Among the data on complications in published studies, COPD exacerbation rates are 9.3-64.0\%, pneumonia rates are $0-11.7 \%$, pneumothorax rates are $4.2-$ $29.2 \%$, and valve migration and replacement rates are between $1.5 \%$ and $20 \%$ (2). While the COPD exacerbation rates of our patients were similar to these studies, our rate of pneumonia was higher. However, in some of our patients who developed pneumonia, the observation of pneumonia not in the target lung lobe, where BLVR was applied, but in another lung area does not suggest this situation as a procedure-related complication.

One of the limitations of our study is that it was designed as a single center and retrospective study. Since the data of the patients for the first year and later were not available, they could not be used in the study. Lack of long-term results and the low number of cases can be considered as the limitations of our study. For all these reasons, we think that our findings should be supported by larger series and prospective studies.

\section{Conclusion}

When we look at the results of our patients, we can evaluate that BLVR methods are successful in reducing symptoms, with significant improvements in mMRC dyspnea score, CAT score, and BODE index after the procedure, although the number of our patients were few. Significant improvements in pulmonary function test parameters and effort capacity of our patients with treatment in study population, low perioperative and early postoperative complications suggest that the procedure is effective and safe. Although EBV or LVRC treatments for BLVR are advantageous compared to surgical methods in terms of both mortality and morbidity, it should be kept in mind that LVRS or lung transplantation may be required in selected cases. In addition, long-term follow-up data of the patients will reveal the true effectiveness of BLVR treatments.

\section{Ethics}

Ethics Committee Approval: The study was approved by Universty of Health Sciences Turkey, Gülhane Training and Research Hospital, Non-interventional Research Ethics Committee (date: 12.11.2019, approvel number: 19/355).

Informed Consent: Written informed consent form was obtained from each participant.

Peer-review: Externally peer-reviewed.

\section{Authorship Contributions}

Surgical and Medical Practices: C.T., D.D., Concept: A.Ç., C.T., D.D., Design: A.Ç., C.T., D.D., Data Collection or Processing: A.Ç., C.T., D.D., Analysis or Interpretation: C.T., D.D., Literature Search: A.Ç., D.D., Writing: A.Ç., C.T., D.D.

Conflict of Interest: No conflict of interest was declared by the authors.

Financial Disclosure: The authors declared that this study received no financial support.

\section{References}

1. GOLD. Guide to COPD Diagnosis, Management and Prevention: A Guide for Health Care Professionals Paperback. 2019. Available from: http://goldcopd.org/wpcontent/uploads/2018/11/GOLD-2019-POCKET-GUIDEFINAL_WMS.pdf

2. Gülşen A. Bronchoscopic Lung Volume Reduction: A 2018 Review and Update. Turk Thorac J. 2018;19:141-149.

3. Holloway RA, Donnelly LE. Immunopathogenesis of chronic obstructive pulmonary disease. Curr Opin Pulm Med. 2013;19:95-102.

4. Rustagi N, Singh S, Dutt N, et al. Efficacy and Safety of Stent, Valves, Vapour ablation, Coils and Sealant Therapies 
in Advanced Emphysema: A Meta-Analysis. Turk Thorac J. 2019;20:43-60.

5. van Agteren JE, Hnin K, Grosser D, Carson KV, Smith BJ. Bronchoscopic lung volume reduction procedures for chronic obstructive pulmonary disease. Cochrane Database Syst Rev. 2017;2:CD012158.

6. Davey C, Zoumot Z, Jordan S, et al. Bronchoscopic lung volume reduction with endobronchial valves for patients with heterogeneous emphysema and intact interlobar fissures (the BeLieVeR-HIFi study): a randomised controlled trial. Lancet. 2015;386:1066-1073.

7. Gompelmann D, Sarmand N, Herth FJ. Interventional pulmonology in chronic obstructive pulmonary disease. Curr Opin Pulm Med. 2017;23:261-268.

8. Yorgancıoğlu A, Polatlı M, Aydemir Ö, et al. KOAH değerlendirme testinin Türkçe geçerlilik ve güvenilirliği [Reliability and validity of Turkish version of COPD assessment test]. Tuberk Toraks. 2012;60:314-320.

9. ATS Committee on Proficiency Standards for Clinical Pulmonary Function Laboratories. ATS statement: guidelines for the six-minute walk test. Am J Respir Crit Care Med. 2002;166:111-117.

10. Ambrosino $\mathrm{N}$, Simonds $\mathrm{A}$. The clinical management in extremely severe COPD. Respir Med. 2007;101:16131624.

11. GOLD, Global Initiative for Chronic Obstructive Lung Disease. 2017. Available from: https://goldcopd.org/ archived-reports/

12. Herth FJF, Slebos DJ, Criner GJ, Shah PL. Endoscopic Lung Volume Reduction: An Expert Panel Recommendation - Update 2017. Respiration. 2017;94:380-388.

13. Deslée $\mathrm{G}$, Mal H, Dutau $\mathrm{H}$, et al. Lung Volume Reduction Coil Treatment vs Usual Care in Patients With Severe Emphysema: The REVOLENS Randomized Clinical Trial. JAMA. 2016;315:175-184.
14. Sciurba FC, Criner GJ, Strange C, et al. Effect of Endobronchial Coils vs Usual Care on Exercise Tolerance in Patients With Severe Emphysema: The RENEW Randomized Clinical Trial. JAMA. 2016;315:2178-2189.

15. Klooster K, Hartman JE, Ten Hacken NH, Slebos DJ. OneYear Follow-Up after Endobronchial Valve Treatment in Patients with Emphysema without Collateral Ventilation Treated in the STELVIO Trial. Respiration. 2017;93:112121.

16. Kemp SV, Slebos DJ, KirkA, et al. AMulticenter Randomized Controlled Trial of Zephyr Endobronchial Valve Treatment in Heterogeneous Emphysema (TRANSFORM). Am J Respir Crit Care Med. 2017;196:1535-1543.

17. Valipour A, Slebos DJ, Herth F, et al. Endobronchial Valve Therapy in Patients with Homogeneous Emphysema. Results from the IMPACT Study. Am J Respir Crit Care Med. 2016;194:1073-1082.

18. Fiorelli A, Santoriello C, De Felice A, et al. Bronchoscopic lung volume reduction with endobronchial valves for heterogeneous emphysema: long-term results. J Vis Surg. $2017 ; 3: 170$

19. Slebos DJ, Hartman JE, Klooster K, et al. Bronchoscopic Coil Treatment for Patients with Severe Emphysema: A Meta-Analysis. Respiration. 2015;90:136-145.

20. LiS, Wang G, Wang C, etal. The REACH Trial:ARandomized Controlled Trial Assessing the Safety and Effectiveness of the Spiration $®$ Valve System in the Treatment of Severe Emphysema. Respiration. 2019;97:416-427.

21. Herth FJ, Noppen M, Valipour A, et al. Efficacy predictors of lung volume reduction with Zephyr valves in a European cohort. Eur Respir J. 2012;39:1334-1342.

22. Tanrıverdi E, Doğan D, Turan D, et al. The impact of coexisting comorbid diseases on long-term mortality in bronchoscopic lung volume reduction. Med Glas (Zenica). 2020;17:73-78. 